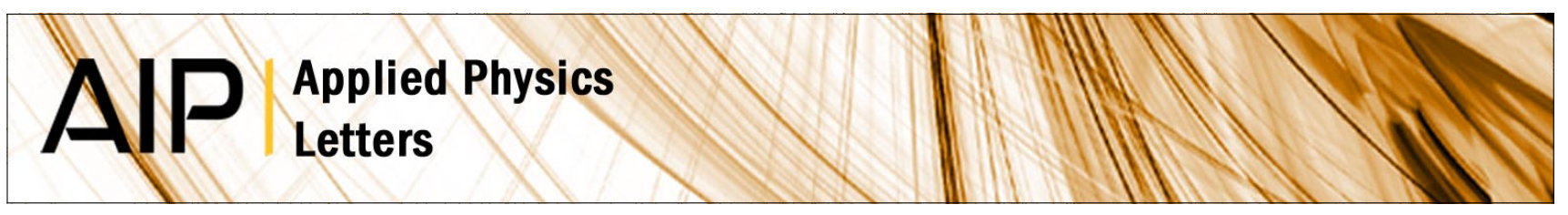

\title{
Semiconductor nanoring lasers
}

Min W. Kim and P.-C. Ku

Citation: Appl. Phys. Lett. 98, 201105 (2011); doi: 10.1063/1.3592739

View online: http://dx.doi.org/10.1063/1.3592739

View Table of Contents: http://apl.aip.org/resource/1/APPLAB/v98/i20

Published by the AIP Publishing LLC.

\section{Additional information on Appl. Phys. Lett.}

Journal Homepage: http://apl.aip.org/

Journal Information: http://apl.aip.org/about/about_the_journal

Top downloads: http://apl.aip.org/features/most_downloaded

Information for Authors: http://apl.aip.org/authors

\section{ADVERTISEMENT}
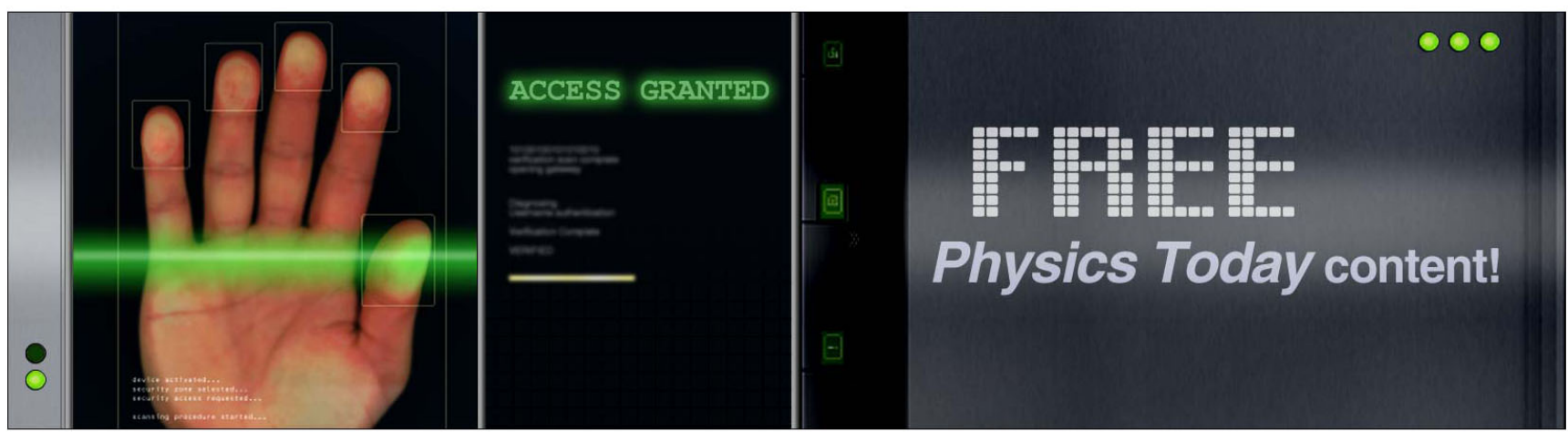


\title{
Semiconductor nanoring lasers
}

\author{
Min W. Kim ${ }^{\text {a) }}$ and P.-C. Ku ${ }^{\text {b) }}$ \\ Department of Electrical Engineering and Computer Science, University of Michigan, 1301 Beal Avenue, \\ Ann Arbor, Michigan 48109, USA
}

(Received 11 March 2011; accepted 29 April 2011; published online 18 May 2011)

\begin{abstract}
Lasing in a subwavelength metal-clad nanoring resonator has been demonstrated with a tunable emission wavelength, controlled by the width of the ring. The emission wavelength is shown to be tunable within a $10 \mathrm{~nm}$ wavelength range by changing the ring width between 240 and $340 \mathrm{~nm}$. This property is expected to mitigate a common nanolaser problem of fine-tuning the emission wavelength without significantly changing the laser dimensions. (C) 2011 American Institute of Physics. [doi:10.1063/1.3592739]
\end{abstract}

As the demand for interconnect speed and architectural complexity increases, the optical interconnect is a potential candidate for future intrachip and interchip communications, offering a higher bandwidth at lower energy consumption., A dense optical interconnect network requires nanoscale components to be compatible with electronic components. In addition to nanoscale optical modulators, waveguides, and photodetectors, nanoscale ring resonators can provide most of the remaining functions that are needed including both passive signal processing such as add-drop filtering, ${ }^{3}$ dispersion compensation, ${ }^{4}$ and signal buffering ${ }^{5}$ as well as active light generation and manipulation such as lasers ${ }^{6,7}$ and switches. Furthermore, a ring resonator can be lithographically defined and evanescently coupled to an optical waveguide. Therefore, high density integration of ring resonators of different functions is possible. In this letter, we will present the experimental demonstration of a subwavelength ring laser with a tunable emission wavelength. As will be shown, the semiconductor nanoring laser is suitable for the optical interconnect application because it possesses unique advantages that include a traveling-wave cavity without a need for additional feedback structures, convenient in-plane coupling to an output waveguide, and independent control of emission wavelength from the device size. ${ }^{8}$

One problem with typical nanolasers is that, due to nanolasers' innate nature of short cavity length, their free spectral range is usually very large. ${ }^{9-15}$ Therefore, it is difficult to fine-tune lasing wavelengths while scaling the laser dimensions. To mitigate this problem, metal-clad semiconductor nanoring lasers were proposed previously. ${ }^{8}$ The metalcladding enables tighter confinement of electric field inside the semiconductor via a hybrid dielectric-plasmonic confinement. The nanoring laser has two parameters that control the resonance wavelength, ring diameter, and width, which make it easier to control lasing wavelength and dimensions independently. For example, semiconductor nanoring laser's outer diameter can stay constant while controlling the lasing wavelength using ring width. The two parameters can be used together to optimize the cavity $\mathrm{Q}$ factor. ${ }^{8}$ This results in constant overall laser dimensions with multiple possible lasing wavelengths within a small range, making the semiconductor nanoring lasers attractive for on-chip use for a couple

\footnotetext{
${ }^{a)}$ Electronic mail: minwkim@umich.edu.

${ }^{b)}$ Electronic mail: peicheng@umich.edu.
}

of reasons. First, constant physical dimensions make the placement of nanoring lasers exhibiting different output wavelengths in an ultradense layout easier. Second, the possibility of multiple wavelengths within a small range makes on-chip wavelength-division multiplexing possible, enabling a more efficient on-chip optical interconnect network. While it is true that gratings have been a preferred choice for resonance wavelength control for larger laser cavities, it is quite difficult to integrate other wavelength-controlling feedback structures such as gratings into a nanoscale laser cavity because of the size. Therefore, as dimensions become smaller, multiple design parameters give an added advantage of wavelength control. In this letter, we experimentally demonstrate a metal-clad subwavelength nanoring laser with a $1.2 \mu \mathrm{m}$ diameter $0.9 \lambda_{\mathrm{o}}$ and $0.8 \lambda_{\mathrm{o}}$ height using plasmonic structures. Furthermore, we demonstrate the tuning of the lasing wavelength via the ring width while keeping the laser dimensions constant.

The sample preparation is described in the following. The InGaAsP/InP epiwafer was grown by the metal-organic chemical vapor deposition technique. All layers are latticematched to InP, and the index contrast provides the necessary vertical confinement. To define the ring, $200 \mathrm{~nm}$ of silicon nitride and $50 \mathrm{~nm}$ of $\mathrm{Cr}$ were deposited as a hard mask via e-beam evaporation and electron beam lithography with a negative resist [hydrogen silsesquioxane (HSQ)] was used for patterning. HSQ was spin-coated at $3000 \mathrm{rpm}$ for $50 \mathrm{~s}$ and baked at $180{ }^{\circ} \mathrm{C}$ for $2 \mathrm{~min}$ on a hot plate. Area dose of $700 \mu \mathrm{C} / \mathrm{cm}^{2}$ with $20 \mathrm{kV}$ acceleration voltage and $10 \mu \mathrm{m}$ aperture was used in Raith 150. The pattern was developed in AZ 400K:DI $\mathrm{H}_{2} \mathrm{O}$ (1:4) for $40 \mathrm{~s}$. Subsequently, the InGaAsP/InP epiwafer was dry etched in a $\mathrm{CH}_{4} / \mathrm{H}_{2} / \mathrm{Ar}$ environment (4 sccm/28 sccm/14 sccm) environment using PlasmaTherm 790. The pressure and power were maintained at $30 \mathrm{~m}$ Torr and $200 \mathrm{~W}$, respectively. During the InP etching, polymer was deposited as a byproduct and was removed using an $\mathrm{O}_{2}$ ashing cycle (70 sccm, $200 \mathrm{mTorr}, 100 \mathrm{~W}, 3 \mathrm{~min}$ ). Once the semiconductor rings were formed, $10 \mathrm{~nm}$ of $\mathrm{Al}_{2} \mathrm{O}_{3}$ was deposited via atomic layer deposition as an insulator to separate the semiconductor from subsequent metal coverage. For conformal metal coverage, a combination of sputtering and electrodeposition was used. A thin layer $(20 \mathrm{~nm})$ of gold $\mathrm{Au}$ ) was first sputtered as a conductive layer. Then, electrodeposition was followed for $300 \mathrm{~nm}$. Scanning electron micrographs of a semiconductor nanoring laser of $1.2 \mu \mathrm{m}$ 

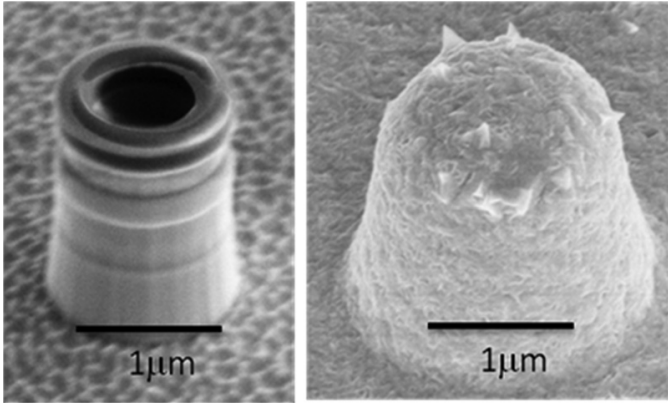

FIG. 1. Scanning electron micrograph of a $1.2 \mu \mathrm{m}$ diameter semiconductor nanoring laser after etching, prior to metal deposition (left) and after metal deposition (right).

diameter before and after the metal deposition are shown in Fig. 1. The device diameter is defined as the outer diameter of the semiconductor part of the ring. According to threedimensional finite-difference-time-domain (3D-FDTD) simulation, it is a single-transverse-mode laser.

Microphotoluminescence ( $\mu$-PL) measurement was carried out to demonstrate lasing in the $1.2 \mu \mathrm{m}$ metal-clad nanoring cavity. The measurement was performed with the substrate kept at $10 \mathrm{~K}$ to minimize nonradiative recombination processes. A standard $\mu$-PL was used with a $1064 \mathrm{~nm}$ wavelength continuous-wave pump laser. Spontaneous emission was collected by an objective lens with a numerical aperture of 0.55 , which was subsequently dispersed by a $0.5 \mathrm{~m}$ focal-length Princeton-Acton monochrometer and detected by a cooled InGaAs photodetector using a lock-in amplifier. Results of the measurement are shown in Fig. 2. Progression of a lasing peak is clearly seen in the figure. Along with the stimulated emission, spontaneous emission also becomes broader. The PL data are analyzed further, and the pump power versus peak PL intensity is plotted in Fig. 3. Transition from spontaneous to stimulated emission occurred at the pump power of $10 \mathrm{~mW}$. Compared to a larger $4 \mu \mathrm{m}$ microring laser, ${ }^{16}$ which had the threshold at the pump power of $21.5 \mathrm{~mW}$, the smaller metal-clad nanoring cavity has a much smaller threshold to lasing. Of the $10 \mathrm{~mW}$ of pump power, only a small fraction actually corresponds to pump absorbed by the active region. Assuming a $6 \mu \mathrm{m}$ diameter of focused laser spot, the actual absorbed power is $50 \mu \mathrm{W}$. For a $4 \mu \mathrm{m}$ diameter microring laser, an actual absorbed power

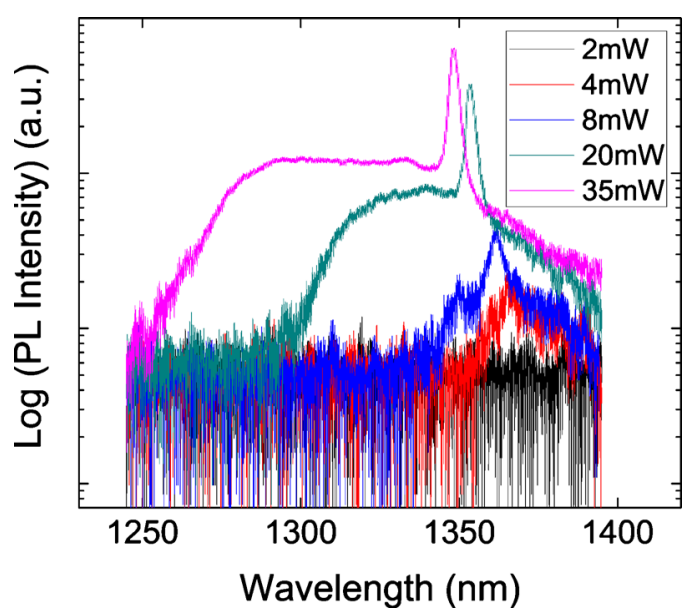

FIG. 2. (Color online) Intensity-dependent $\mu$-PL of a $1.2 \mu$ m-diameter metal-clad ring laser with $250 \mathrm{~nm}$ ring width.

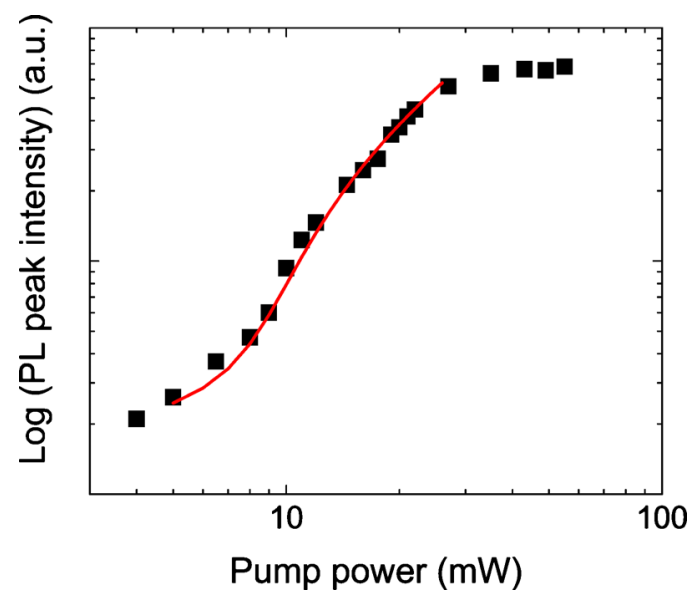

FIG. 3. (Color online) Pump power vs peak PL intensity of $1.2 \mu \mathrm{m}$ diameter metal-clad nanoring.

of $1.2 \mathrm{~mW}$ was reported in Ref. 16. This is expected as the smaller mode volume of the $1.2 \mu \mathrm{m}$ nanoring cavity is expected to lower the threshold pump power. The mode volume of the metal-clad nanoring resonator cavity of $1.2 \mu \mathrm{m}$ diameter is calculated to be $0.004 \mu \mathrm{m}^{3}$. Furthermore, the L-L curve in Fig. 3 was fitted with the laser rate equations as was done for a $4 \mu \mathrm{m}$-diameter microring resonator in Ref. 16. The $1.2 \mu \mathrm{m}$ nanoring laser has a spontaneous emission coupling factor, $\beta$, of 0.01 while the $4 \mu \mathrm{m}$-diameter microring laser had $\beta$ of $5 \times 10^{-4}$. The higher $\beta$ factor also leads to decreased threshold pump power, as observed in Fig. 3. Additionally, the $1.2 \mu \mathrm{m}$ diameter nanoring cavity shows a saturation behavior as the pump power exceeds $40 \mathrm{~mW}$. This was attributed to sample heating. In the experiment, the focused laser spot was about $6 \mu \mathrm{m}$ in diameter and any laser power that hit outside the resonator area contributed to sample heating.

Figure 4 shows the linewidth and peak wavelength as a function of the pump power. The PL data from Fig. 2 were fitted with a Lorenzian function to determine the laser linewidth. A clear linewidth collapse was observed at the laser threshold and the linewidth was $2.3 \mathrm{~nm}$ above the laser threshold. The lasing wavelength continuously decreased with the increasing pump power, possibly due to band filling, although the lasing wavelength seemed to be settling at a high pump power. This is explained by the thermally induced redshift at the high pump power that compensates the blue shift.

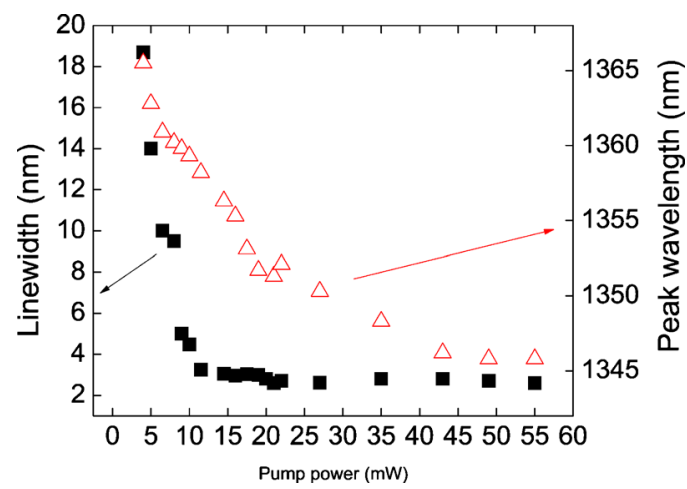

FIG. 4. (Color online) Linewidth and peak wavelength vs pump power of $1.2 \mu \mathrm{m}$ diameter metal-clad nanoring. 


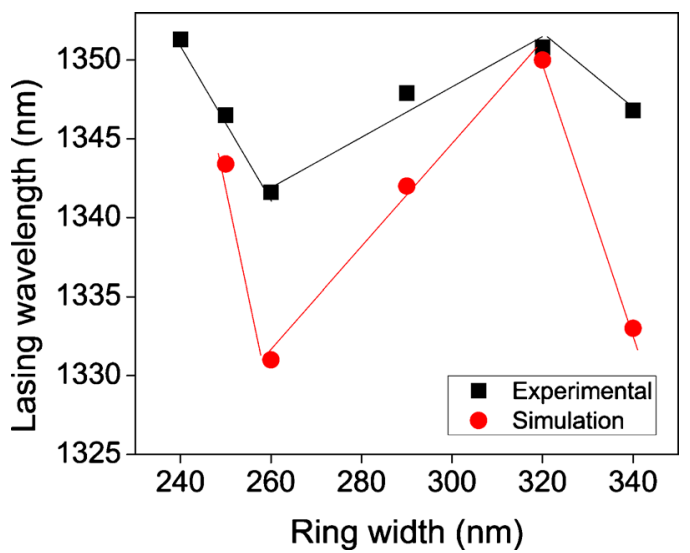

FIG. 5. (Color online) Lasing wavelength shift due to ring width variation. Lines are for visual guidance only.

To demonstrate wavelength tuning, metal-clad nanoring lasers of $1.2 \mu \mathrm{m}$ diameter with various ring widths were fabricated and measured using the identical optical measurement scheme described above. The results are shown in Fig. 5 . It can be clearly seen that, by altering the ring width between 240 and $340 \mathrm{~nm}$, the lasing wavelength can be finetuned to within a $10 \mathrm{~nm}$ range. The oscillatory behavior of the lasing wavelength is due to the shift of nearby resonance peaks in and out of the spontaneous emission range of the epistructure. According to the 3D-FDTD simulations, the resonance peaks undergo a redshift behavior with increasing ring width, in general. In Fig. 5, resonance peaks within the spontaneous emission range of the epistructure from 3DFDTD simulations are plotted along with the experimental data. The trend agrees well with the experiment. The discrepancy of the lasing wavelengths may be due to the passive active region assumed in the calculations.

In summary, lasing in a $1.2 \mu \mathrm{m}$ diameter subwavelength metal-clad nanoring resonator has been demonstrated with a tunable emission wavelength controlled by the width of the ring. A relatively large spontaneous emission factor 0.01 was measured, which was attributed to the small modal volume. The emission wavelength can be tuned for a $10 \mathrm{~nm}$ wavelength range by changing the ring width from 240 to $340 \mathrm{~nm}$.

This letter was supported by the DARPA/MTO NACHOS program (Grant No. W911NF-07-1-031 3) and was partially performed in the Lurie Nanofabrication Facility, which is part of the NSF NNIN network.

${ }^{1}$ R. G. Beausoleil, P. J. Kuekes, G. S. Snider, S. Y. Wang, and R. S. Williams, Proc. IEEE 96, 230 (2008).

${ }^{2}$ D. A. B. Miller, Proc. IEEE 88, 728 (2000).

${ }^{3}$ B. E. Little, S. T. Chu, H. A. Haus, J. S. Foresi, and J.-P. Laine, J. Lightwave Technol. 15, 998 (1997).

${ }^{4}$ G. Lenz and C. K. Madsen, J. Lightwave Technol. 17, 1248 (1999).

${ }^{5}$ F. N. Xia, L. Sekaric, and Y. Vlasov, Nat. Photonics 1, 65 (2007).

${ }^{6}$ D. R. Scifres, R. D. Burnham, and W. Streifer, Appl. Phys. Lett. 28, 681 (1976).

${ }^{7}$ N. Matsumoto and K. Kumabe, Jpn. J. Appl. Phys., Part 1 16, 1395 (1977).

${ }^{8}$ M. Kim and P. C. Ku, Opt. Express 19, 3218 (2011).

${ }^{9}$ N. Yu, E. Cubukcu, L. Diehl, D. Bour, S. Corzine, J. Zhu, G. Hofler, K. Crozier, and F. Capasso, Opt. Express 15, 13272 (2007).

${ }^{10}$ S.-W. Chang and S.-L. Chuang, Opt. Express 16, 10580 (2008).

${ }^{11}$ M. T. Hill, Y.-S. Oei, B. Smalbrugge, Y. Zhu, T. De Vries, P. J. Van Veldhoven, F. W. M. Van Otten, T. J. Eijkemans, J. P. Turkiewicz, H. De Waardt, E. Jan Geluk, S.-H. Kwon, Y.-H. Lee, R. Notzel, and M. K. Smit, Nat. Photonics 1, 589 (2007).

${ }^{12}$ M. T. Hill, M. Marell, E. S. P. Leong, B. Smalbrugge, Y. Zhu, M. Sun, P. J. Van Veldhoven, E. Jan Geluk, F. Karouta, Y.-S. Oei, R. Notzel, C.-Z. Ning, and M. K. Smit, Opt. Express 17, 11107 (2009).

${ }^{13}$ R. F. Oulton, V. J. Sorger, T. Zentgraf, R.-M. Ma, C. Gladden, L. Dai, G. Bartal, and X. Zhang, Nature (London) 461, 629 (2009).

${ }^{14}$ M. A. Noginov, G. Zhu, A. M. Belgrave, R. Bakker, V. M. Shalaev, E. E. Narimanov, S. Stout, E. Herz, T. Suteewong, and U. Wiesner, Nature (London) 460, 1110 (2009).

${ }^{15}$ K. Yu, A. Lakhani, and M. C. Wu, Opt. Express 18, 8790 (2010).

${ }^{16}$ M. Kim and P. C. Ku, Appl. Phys. Lett. 98, 131107 (2011). 